\title{
ACERCA DA METAPSICOLOGIA DOS LIMITES
}

Camila Junqueira e Nelson Ernesto Coelho Junior

Camila Junqueira

Membro do

Departamento

de Psicanálise do

RESUMO: A "metapsicologia dos limites" pode ser definida como Instituto Sedes Sapientiae, São Paulo, Brasil

Nelson Ernesto Coelho Junior

Universidade de São Paulo (USP), Instituto de Psicologia, São Paulo/SP, Brasil a parte da teoria psicanalítica que visa compreender a estruturação e o funcionamento dos limites do psiquismo; bem como, a parte da teoria psicanalítica que se destina a compreender a etiologia, o funcionamento e o tratamento dessas patologias-limite. O objetivo deste texto é apresentar uma articulação entre ideias de Freud, Winnicott, Green e Brusset que nos permitiram organizar uma hipótese etiológica para esses quadros que os situa dentro das neuroses narcísicas, mas os diferencia das melancolias, e examinar as consequências tópicas dessa hipótese, procurando contribuir com o campo da metapsicologia dos limites.

Palavras-chave: pacientes-limite; etiologia; tópica; terceira tópica.

ABSTRACT: The metapsychology of psychic borders. The metapsychology of psychic borders can be defined as a part of the psychoanalysis which aims to understand the organization and the operation of the psychic borders; and also as a part of the psychoanalytical theory which aims to understand the etiology, operation and treatment of borderline pathologies. The aim of this paper is to present an articulation between the ideas of Freud, Winnicott, Green and Brusset. This allowed us to construct an etiology hypothesis which places this condition within the narcissistic neuroses, however, differentiates it from melancholy. We also examined the topic consequences of this hypothesis, seeking to contribute to the field of metapsychology of psychic borders.

Keywords: borderline, etiology, topic, third topic. 
$\mathrm{N}$ os últimos anos, tem ficado cada vez mais evidente que certas manifestações, tais como as adicções, as doenças psicossomáticas, os distúrbios alimentares e certas depressões, dentre outras, não podem mais ser reduzidas às estruturas nosológicas clássicas, como a neurose, a psicose e a perversão. Esses casos não são propriamente novos, mas têm cada vez mais despertado o interesse dos psicanalistas. A compreensão desses pacientes tem sido realizada dentro do amplo espectro das "patologias-limite", "estados-limite”, transtornos borderline etc., e são envoltas por uma variedade bastante grande de versões acerca de sua gênese e de seu funcionamento: Winnicott (1992/1945, 1992/1954a, 1986/1954b, 1984/1963), entre outros textos; Kernberg (1967, 1984, 1985, 2001), entre outros textos; Searles (1986); Green (1995, 1999, 2002, 2008); Fonagy (1998); Fonagy et al (2003), Brusset (1999, 2003, 2005, 2006); André (2004); e Roussillon (2004, 2007, 2008); dentre outros.

Diante disso, a "metapsicologia dos limites" poderia ser definida, de modo geral, como a parte da teoria psicanalítica que visa compreender a estruturação e o funcionamento dos limites do psiquismo; e, de modo específico, como a parte da teoria psicanalítica que se destina a compreender a etiologia, o funcionamento e o tratamento dessas patologias-limite, manifestações decorrentes de falhas na constituição e no funcionamento dos limites do psiquismo.

Grosso modo, a escola inglesa concebe o borderline como um quadro clínico específico com estrutura própria, o que justifica uma modalidade singular de tratamento; um quadro que fica na fronteira entre a neurose e a psicose, e que se diferencia da perversão. Já a escola francesa, que prefere o termo "estados-limite", acredita que esses não se configuram como uma estrutura, sendo mais uma modalidade transitória de funcionamento psíquico presente nas neuroses graves e nas perversões (VILLA; CARDOSO, 2004). Há também um grupo de psicanalistas lacanianos que defende o uso do termo "pacientes inclassificáveis", pois não se enquadram nas estruturas clínicas propostas por Lacan (MILLER, 1998). Também consideramos significativo o termo “patologias atuais”, proposto por Mayer (2001), que indica uma condensação entre as patologias que estão aparecendo com maior frequência na atualidade e aquelas caracterizadas pela atuação (acting out, passagem ao ato e enactment), pois são essas repetidas atuações que marcam as dificuldades técnicas na clínica desses pacientes. Outros analistas preferem o termo "paciente-limite", pois esses são pacientes que nos colocam no limite da técnica. No entanto, o termo "paciente-limite" nos parece particularmente interessante, já que aponta para a própria constituição dos limites do psiquismo, aspecto que desejamos destacar neste trabalho. Green (2002, 2008) irá propor, ainda, a ampla denominação de "pacientes não-neuróticos".

De acordo com Brusset (1999), já a partir dos anos sessenta houve uma tentativa de afinar a descrição desses casos, diferenciando-os das psicoses e das 
neuroses graves. Os elementos comuns a esses quadros seriam: a importância dada ao Eu; a fragilidade do Eu e de seus mecanismos de defesa; e a angústia maciça e simultânea de intrusão e de perda do objeto, onde os conflitos não são simbolizáveis e onde se apresenta um polimorfismo de sintomas e uma inconsistência nas relações de objeto.

Enquanto a neurose, a psicose e a perversão foram, desde Freud, definidas como conflitos entre as instâncias psíquicas e a realidade, o funcionamento limite se caracteriza por uma precariedade de constituição do aparelho psíquico e, portanto, por uma maior porosidade dos limites entre essas instâncias. Isso não exclui a coexistência de conflitos entre elas, porém, esses pacientes se caracterizam por problemas que ocorrem num outro plano: a constituição das fronteiras e limites do aparelho psíquico e do Eu. Nesse sentido, não compreendemos os pacientes-limite como estando entre a neurose e a psicose, tampouco como submetidos a um estado passageiro proporcionado por um conflito pontual. Estamos alinhados com autores como Green e Brusset, entre outros, que acreditam que o funcionamento limite se forja nos momentos da constituição do psiquismo, entretanto, não exclui o sujeito da passagem pelo Édipo e pelo complexo de castração que definem as organizações clínicas (neurose, psicose e perversão), a partir do mecanismo de defesa utilizado para lidar com essa passagem (recalque, forclusão ou recusa). Porém, nos casos-limite, essas estruturas se apóiam sobre alicerces frágeis, aumentando a complexidade da organização psíquica desses sujeitos. Voltaremos a essa definição a seguir, ao discutir a etiologia dos pacientes-limite.

Entretanto, o objetivo deste texto é, tão somente, apresentar uma articulação entre algumas ideias de Freud, Winnicott, Green e Brusset que nos permitiram organizar uma hipótese etiológica para esses quadros - que os situa dentro do campo das neuroses narcísicas, mas os diferencia das melancolias - e examinar as consequências tópicas dessa hipótese, procurando, desse modo, dar uma contribuição ao campo de discussão da metapsicologia dos limites.

\section{AS PATOLOGIAS-LIMITE COMO UM TIPO ESPECÍFICO DE NEUROSE NARCÍSICA}

A relação entre patologia-limite e narcisismo parece ser um consenso em psicanálise, sendo abordada por diversos autores há várias décadas. Podemos encontrar trabalhos que vão desde textos clássicos como o de Kernberg (1967) a contribuições mais recentes como Roussillon (2008), dentre outros. Entretanto, nos propomos, nesse momento, a revisitar algumas ideias de Freud acerca do narcisismo que nos permitiram construir uma hipótese sobre a gênese das patologias limite e que, junto de algumas das ideias de Green, nos permitem diferenciá-las das melancolias. 
No texto Narcisismo: uma introdução (1914), nas Conferências Introdutórias (1917a), bem como em Luto e Melancolia (1917b), Freud expõe algumas ideias acerca das neuroses narcísicas. Para Freud (1914), o narcisismo é um estádio universal e original no qual as pulsões estão completamente voltadas para si mesmo e, durante o desenvolvimento normal da libido, esta deve se dirigir aos objetos em busca de satisfação, sem que o narcisismo desapareça totalmente. Porém, há situações em que a libido é retirada dos objetos e, nos três textos citados acima, Freud expõe suas ideias acerca das diferentes formas de retirada da libido dos objetos. Quando a libido não encontra mais satisfação nesses objetos, seja pela ausência desses na realidade, seja pelo efeito da repressão, ela passa por um processo denominado nesse texto de introversão, podendo encontrar satisfação nos objetos da fantasia. O sono também figura como um estado em que a libido é retirada dos objetos. Porém, a depender do tipo de relação com o objeto, bem como da intensidade da retirada da libido dos objetos e da regressão para o Eu, esse processo será responsável pela constituição de uma neurose narcísica (FREUD, 1917a). Ainda de acordo com Freud (1917b), o processo que desliga a libido dos objetos e bloqueia seu retorno a eles é estreitamente relacionado ao processo de repressão. Contudo, se, nas neuroses narcísicas, o resultado é diferente do que ocorre na histeria (psiconeuroses em geral ou neuroses de transferência), isso se deve a fatores constitucionais; ou seja, o ponto de fixação deve ter ocorrido em fases muito mais precoces do desenvolvimento, provavelmente na fase do narcisismo primário. Sabemos também que a retirada de libido dos objetos primários será responsável, através do processo de identificação com os objetos perdidos, pela constituição do Eu e do Supereu, no processo de dissolução do complexo de Édipo, o qual Freud associa ao narcisismo secundário (FREUD, 1923).

Numa leitura sem dúvida já influenciada por diversos autores contemporâneos, como Green (especialmente no que diz respeito ao complexo da mãe-morta, que será abordado adiante), mas também Winnicott (que, entre outros, atribui a constituição do funcionamento borderline às vicissitudes da relação mãe-bebê), propomos que o que ocorre nesses pacientes é uma fixação no narcisismo primário; a pulsão, ou pelo menos boa parte dela, não se torna objetal devido à falta de uma relação de objeto estável com um objeto de confiança. Nesse sentido, estamos procurando sustentar a ideia de que, ao invés de uma regressão da libido, como ocorre na maioria das neuroses narcísicas, as patologias-limite se constituem como um tipo específico de neurose narcísica, onde há um "não-desenvolvimento", ainda que parcial, da pulsão e uma retenção desta no narcisismo primário. Isso ocorreria devido à ausência de um objeto libidinal primário confiável e estável ao qual a libido possa se ligar. Esse não desenvolvimento, ainda que parcial, da pulsão compromete a constituição do Eu e das fronteiras psíquicas que dependem para sua formação da retirada da libido dos objetos. O 
Eu e as fronteiras psíquicas se constituem então de forma frágil e demasiadamente porosa. Em resumo, enquanto certas neuroses narcísicas se constituem a partir de uma regressão da libido, as patologias-limite, compreendidas como um tipo especial de neurose narcísica, se constituem a partir de um não-desenvolvimento parcial da pulsão e de seu represamento no narcisismo primário.

Contudo, essa afirmação gera a necessidade de uma revisão da tópica freudiana que dê lugar ao narcisismo primário, onde a pulsão ficaria então represada ${ }^{1}$. Como dissemos, esse represamento não seria no Eu, pois a pulsão ficaria retida antes mesmo da constituição deste. A libido ficaria assim represada num lugar que antecede a própria constituição do psiquismo tal como Freud o concebeu, no encontro da pulsão com o objeto. Daí pensá-lo como lugar fora-do-psíquico e relacioná-lo com um estado anobjetal.

O psiquismo seria então definido como sendo a parte organizada do Self (si-mesmo) com vistas a dar lugar à tensão libidinal, e o Self compreenderia tanto o psíquico como o não-psíquico; como explicitaremos melhor adiante. Essa localização não-psíquica se justifica pelo fato de a pulsão represada ser percebida como traumática (não representada), assim como explica a grande dificuldade de transferência desses pacientes; pois não encontra meios de ser acolhida simbolicamente pelo psiquismo.

Considerar as patologias-limite como neuroses narcísicas para as quais não há propriamente uma regressão, mas, sim, um acúmulo de pulsão mais primário é também importante. Isso permite diferenciar a gênese dessas patologias da gênese das melancolias. Essa diferenciação não tem a intenção de desconsiderar que, após a instalação do quadro, a descrição do funcionamento dessas e das melancolias podem se assemelhar muito e que, na clínica, nunca imaginamos encontrar casos "puros” de uma ou outra patologia. No entanto, parece importante diferenciar que, na melancolia, há a perda de um objeto com o qual se tinha uma relação ambivalente e uma identificação de tipo narcísico, onde a libido retirada do objeto regride para o Eu já constituído (FREUD, 1917b). Diferentemente disso, nas patologias-limite parece haver um represamento da pulsão no Self, anterior à própria constituição do Eu, fruto de uma relação de objeto parca ou inexistente e que compromete a constituição do Eu. A diferença, na gênese, é importante para a clínica. Se, na melancolia, trata-se de dissipar a sombra do objeto que recai sobre o Eu, nas patologias-limite, trata-se de ajudar o paciente a ir de encontro a um objeto primário estável e confiável, tal como deve ser a mãe suficientemente boa que, através da identificação com o seu bebê, percebe o momento de desiludi-lo. E, assim, opera na constituição da diferenciação entre

\footnotetext{
${ }^{1}$ Evidentemente, essa pulsão que não encontra objeto, e que, portanto, não pode ser denominada de libido, deve ser pensada como pulsão de morte, definida por Freud (1920) como pulsão sem objeto. Contudo, esperamos voltar a esses desdobramentos em outro trabalho.
} 
o dentro e o fora, na relação com a realidade e, mais adiante, na constituição do Eu e dos demais limites do psiquismo.

Na esteira do que Green (1980) propõe acerca do “complexo da mãe morta”, podemos compreender que os pacientes-limite não são melancólicos e, sim, filhos de pais melancólicos enredados uma trama transgeracional. De acordo com Green, o “complexo da mãe-morta” se introduz quando a mãe é violentamente abatida por um luto ou por uma ferida narcísica (aborto ou traição do marido, por exemplo) nos momentos mais iniciais da vida do bebê, e, como resultado do desinvestimento da mãe no bebê, há um desinvestimento do bebê na mãe e uma identificação inconsciente como a mãe morta. A “identificação negativa” postulada por Green é a identificação não com o objeto, mas com o vazio, pelo desinvestimento, próximo do que o casal Abraham e Torok (1994) nomeia de identificação endocríptica. Os vazios psíquicos são causados pela falta de investimento da mãe na criança e são mantidos pela destrutividade que é liberada com o enfraquecimento do investimento erótico. O ódio maciço, nesses casos, é então explicado por Green (1975/1988) como um processo de desintrincamento pulsional, a que nós poderíamos, a partir de nossa hipótese, acrescer um processo de não-intrincamento promovido pela retenção da pulsão no narcisismo primário, um estado que compreendemos como anobjetal onde impera a pulsão de morte.

Dessa forma, o que o complexo da mãe-morta, como protótipo da etiologia das patologias-limite, nos sugere é que o que ocorre nessas patologias é a ausência ou a inconsistência de uma relação primária de objeto da qual depende a constituição do Eu através do processo de identificação, como já havia sido de certo modo apontado pela teoria winnicottiana do funcionamento borderline. Essa ideia corrobora nossa hipótese de um represamento no narcisismo primário, anterior à constituição do Eu e da estruturação do psiquismo, que implica em pensar em um aquém do psíquico, fora-do-psíquico ou não-psíquico, que será mais amplamente abordado na sequência.

Nesse sentido, retomando a compreensão de paciente-limite adotada por nós e apresentada no início do texto, pode-se afirmar que o funcionamento limite não está entre a neurose e a psicose, tampouco se resume a um estado passageiro ou transitório. O funcionamento limite se formaria nos momentos de encontro e de desencontros com o objeto primário que, capturando a libido, deveria contribuir para a constituição dos limites do psiquismo de modo geral — e do Eu de modo específico — através da constituição das "vias facilitadas", marcas mnênicas e traços deixados por seus repetidos investimentos, tal como nos ensina Freud desde o Projeto (1895). Todavia, nesses casos, a não captura de parte suficiente da pulsão pelo objeto faz com que permaneça represada no narcisismo primário, no Self — fora do psiquismo. Evidentemente, se toda libido 
ficasse represada fora do psiquismo, não haveria sujeito, como se pode pensar para certos casos de autismo. Contudo, nos casos limite, a parte da libido que consegue se ligar a algum objeto se desenvolve constituindo alguma estrutura psíquica e um Eu, ainda que frágil e demasiadamente poroso. E será sobre esse psiquismo que a passagem pelo Édipo e pela castração deixará suas marcas. Isso nos permite encontrar pacientes-limite com funcionamento histérico, obsessivo, fóbico, psicótico ou ainda perverso, de modo concomitante, predominante ou não ao funcionamento limite.

\section{REORGANIZAÇÃO DA TÓPICA PSÍQUICA}

Ao afirmar que, nas patologias-limite, a pulsão ficaria represada fora-do-psíquico, não podemos nos esquivar de ao menos tentar circunscrever que lugar é esse; o que nos levou nos debruçar sobre o estudo de uma reorganização da tópica que implicou uma definição própria do conceito de Self.

Como Green $(1988 / 1975,2002)$ bem destaca, o Self é um dos produtos mais recentes e mais diversos da psicanálise contemporânea. Para quem se interessa sobre as diversas definições pelas quais esse conceito passou, remetemos o leitor aos trabalhos de Meissner (1986), dentre outros (BLUM, 1982; TICHO, 1982; HAVENS, 1986, SOCCOR, 1997). Para efeito de nosso trabalho, cabe apenas deixar claro que estaremos compreendo o Self como indicativo de uma localização tópica. O Self é tomado aqui como a pessoa total em excluindo o corpo biológico, e o aparelho psíquico é compreendido como a parte organizada do Self com vistas a dar um destino às excitações proveniente do corpo e do mundo externo. Nesse sentido, é necessário pensarmos um lugar para as excitações que não encontram destino, para a energia que não é transformada.

Assim sendo, o conteúdo do fora-do-psíquico seria a energia que provém tanto das excitações endógenas como das exógenas ${ }^{2}$ e que não encontra destino, descarga ou satisfação. Ela realiza sobre o aparelho um efeito de pressão, de excesso, que geralmente relacionamos às experiências traumáticas, bem como aos efeitos da anobjetalidade (estado auto-erótico em que ainda não se constituiu diferença suficiente entre Eu e objeto, no qual que se mantém a indiferenciação primária), da clivagem e da recusa, tão característicos das patologias-limite. Ou seja, relacionada com aquilo que está aquém da primeira e da segunda tópicas freudianas e que, portanto, exige uma reorganização dos espaços psíquicos para que seu lugar seja apontado.

\footnotetext{
${ }^{2}$ Os estímulos exógenos são aqueles que provêm dos objetos externos, fazendo referência à ideia de Green de que o objeto também desperta a pulsão.
} 
Green, em 1975, já sugere a necessidade de uma nova tópica que dê conta das relações entre o Self e o objeto. No entanto, ao longo de sua obra, Green parece por fim se interessar muito mais em pensar o trânsito entre os espaços, que resultou no conceito de processos terciários ${ }^{3}$, do que propriamente numa nova reorganização tópica. Contudo, suas ideias foram importantes para diversos autores.

Atualmente, já existem vários autores que trabalham com a idéia de uma terceira tópica, como bem resume Brusset (2006), autor cujas ideias são referência para esta proposta. Para este autor, a terceira tópica é o resultado da articulação entre o intrapsíquico de Freud e o intersubjetivo do modelo transicional; da identificação projetiva; da noção de indiferenciação primária; além da clínica com pacientes-limite, que ele sugere denominar "pacientes com funcionamento psíquico em exterioridade"; ou seja, funcionamentos psíquicos em que o que está fora do aparelho psíquico tem muito mais peso na dinâmica dos acontecimentos psíquicos.

Desse modo, o autor propõe uma nova tópica em continuidade à teoria freudiana. Uma terceira tópica, que antecede a primeira (consciente/inconsciente) e trata da diferenciação entre dentro e fora. Essa tópica pretende dar conta dos efeitos das operações de recusa e de clivagem que produzem elementos localizados fora da rede psíquica, descrevendo o espaço que ocupam os produtos da clivagem e da recusa constitutivos do aparelho psíquico e que não estão apenas relacionados a certas patologias, embora sejam predominantes nas patologias-limite.

Entretanto, apesar de insistir na ideia de uma terceira tópica comum à formação do aparelho psíquico em geral que estaria em relação de anterioridade com a primeira, Brusset aponta que a consideração desta é especialmente importante na compreensão dos pacientes-limite. Na clínica contemporânea, certos modos de funcionamento e sua relação com a realidade externa não são explicados pela primeira nem pela segunda tópicas; nem pelo jogo de representação de coisa e de palavra, segundo o modelo do sonho e da neurose; nem pela estruturação edípica; e nem pelo conflito entre instâncias ou no seio das instâncias. A clínica da identificação projetiva, da passagem ao ato e das somatizações tem atraído interesse e forma o amplo espectro das patologias-limite e das adições. Para essas, o campo comum é a angústia de intrusão e abandono, a problemática dos limites e a indiferenciação entre espaços. Daí a nossa proposta de inverter a máxima de Botella, C. e Botella, S. (2002), mantendo o paradoxo. Para os pacientes-limite, teríamos, então: "Somente fora, também dentro".

\footnotetext{
3 "Por processos terciários compreendo os processos que colocam em relação os processos primários e os secundários de tal modo que os processos primários limitam a saturação dos processos secundários e os processos secundários dos processos primários” (GREEN, 1995, p.152).
} 
Green (2006) argumenta que a noção de vínculo (lien) em que se baseia a terceira tópica proposta por Brusset é uma noção antiga na psicanálise, presente em Freud desde o capítulo VI de a Interpretação dos Sonhos (1900) e seguida de contribuições importantes de Bion e Winnicott. Isso eliminaria qualquer originalidade de Brusset e ainda questiona, sem responder, se a constatação de que certos pacientes não podem ser compreendidos através das duas primeiras tópicas justificaria a tentativa de construção de uma terceira. O curioso no tom ácido do comentário de Green é que, ele próprio, é referência fundamental para o argumento de Brusset, ao ter proposto a possibilidade de um "terceiro modelo topográfico" que contemplasse o objeto e o Self.

Ao que parece, Green e Brusset estão falando de diferentes aspectos do funcionamento psíquico que, possivelmente, são complementares. Brusset dá ênfase para o aspecto tópico, que, em termos greenianos, talvez possa ser compreendido como o primeiro do "duplo limite". Limite esse que marca a diferença entre Eu e Outro, que, por sua vez, faz a diferença entre interno e externo, sobre a qual se apóia todo o restante da organização psíquica. Uma indiferenciação entre esses dois campos não impede o estabelecimento de tal organização, mas certamente influencia intimamente as vicissitudes dessa organização, especialmente no que tange ao trânsito entre os espaços que irão se formar; aspectos que serão justamente o foco de atenção de Green nos últimos anos de sua obra.

Pudemos tecer o esquema a seguir a partir das considerações de Green apresentadas nas Conferências Brasileiras (1975/1990) e retomadas nas Orientações para uma psicanálise contemporânea (2008), nas quais o autor articula, num mesmo esquema gráfico, a primeira e segunda tópicas freudianas com a teoria representacional, dando ênfase ao trânsito da pulsão, representação e objetos nos espaços psíquicos — em articulação com as considerações de Brusset (2006) acerca da terceira tópica, e, ainda, com os ensinamentos de Winnicott sobre os objetos transicionais e o espaço potencial, também formados pelo vai-e-vem dos objetos primários.

O esquema de Green $(1975 / 1990,2008)$ foi redesenhado a fim de adquirir uma forma mais orgânica, mais próxima daquela que Freud expõe no texto 0 Eu e o Id (1923). A ele, foi acrescido a tópica de Winnicott e uma proposta de localização do fora-do-psíquico ou não-psíquico e do Self. Nesse esquema, o Id, que Freud postula como parte do aparelho psíquico, foi reposicionado e passou a ocupar uma zona de fronteira entre o psíquico e o não-psíquico. O aparelho psíquico seria, então, a parte organizada do Self, produto do encontro da pulsão e do objeto e palco dos conflitos neuróticos. Porém, haveria uma parte do Self reservada para o não-psíquico e para os produtos da clivagem e da recusa que implicam num desobjetalização da pulsão, e que se fazem predominantes nos casos-limite. Espaço esse que, na esteira de Brusset, poderia ser denominado de terceira tópica. 
Esquema de Green $(1975 / 1990,2008)$ redesenhado

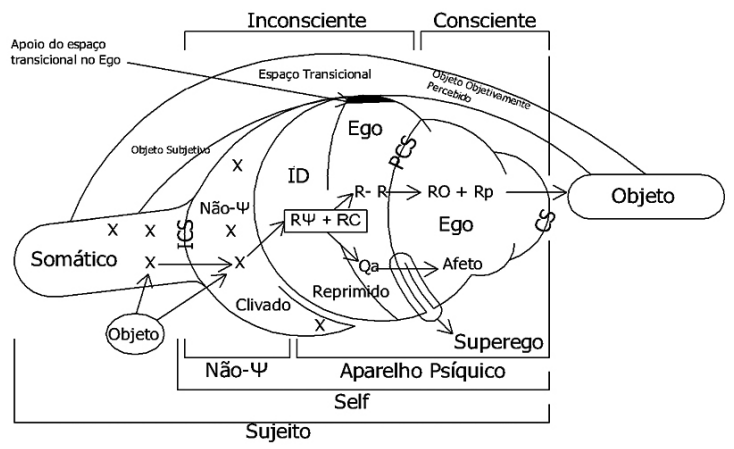

\footnotetext{
- Estrutura Enquadrante (todos os limites)

$S$ - Somático

Não- $\Psi$ - psíquico - 3a tópica - 10 do duplo limite: Eu / Não-Eu

$X$ - Excitação Somática ou estímulo endógeno

ICS - Barreira do inconsciente em relação ao Soma, ou limite Somatopsíquico

PCS - Barreira do pré-consciente

CS - Barreira do consciente, função de percepção e de para-excitação

$R \Psi$ - Representante psíquico da pulsão ou da excitação pulsional que parte de $X$

$R c$ - Representação de coisa inconsciente que junto a $R \Psi$ dá lugar ao

R-R (representante - representação) e a Qa (quantum de afeto)

Ro - Representação coisa / objeto consciente

Rp - Representação palavra
}

A tópica winnicottiana - espaço potencial, objeto subjetivo, objeto objetivamente percebido e objeto transicional — não pode ser simplesmente integrada à tópica freudiana, na medida em que é constituída por outras premissas, como sustentação da ilusão de onipotência como base para o contato com a realidade, ao invés da inscrição de traços e constituição do psiquismo a partir das experiências de satisfação com objetos primários, como em Freud. Porém, acreditamos ser possível estabelecer um ponto de articulação entre essas tópicas que se situa numa coincidência possível entre o objeto externo que satisfaz a pulsão e o objeto externo que sustenta a ilusão de onipotência. Essa ideia foi mais amplamente desenvolvida por um de nós em outro trabalho (JUNQUEIRA, 2010), mas, em resumo, baseia-se em algumas passagens onde o próprio Winnicott aponta essa possível coincidência entre elas. Não há, entre esses objetos (de satisfação pulsional e de sustentação da ilusão de onipotência), uma relação de equivalência, mas, sim, uma possível relação de coincidência, que tem sua relevância para a aproximação da teoria pulsional de Freud com a teoria das relações de objeto de Winnicott.

O que se supõe é a existência de uma relação de suplementaridade entre as tópicas de Freud e Winnicott, entre o espaço transicional e o aparelho psíquico, 
na medida em que ambos se constituem com a finalidade de lidar com a realidade e com as presenças e ausências do objeto, onde o objeto externo é um ponto de contato entre eles. Porém, não se imagina a redução de um objeto ao outro, tampouco a simples integração de uma tópica na outra. Isso porque, enquanto Freud pensa os espaços que formam o aparelho psíquico, Winnicott pensa o espaço que sustenta o desenvolvimento emocional.

Entretanto, o esquema apresentado procura ilustrar graficamente essa suplementaridade. Nele, há três pontos de contato entre o que compreendemos como "dois níveis de apreensão do Self” (aparelho psíquico e desenvolvimento emocional): o somático, o objeto externo e o apoio do espaço potencial no Eu. O somático é, ao mesmo tempo, produtor de estímulos endógenos em busca de satisfação através de objetos, e produtor de necessidades que, quando atendidas dentro de uma experiência de ilusão de onipotência, colaboram para a constituição dos objetos subjetivos. O objeto externo será um ponto de contato sempre que houver uma coincidência entre o objeto da necessidade que satisfaz a ilusão de onipotência e o objeto da pulsão, tal como procuramos argumentar acima. Ainda cabe comentar que essa coincidência permite o desenvolvimento conjunto desses dois processos paralelos (psiquismo e continuidade do Ser) e, desse desenvolvimento conjunto, depende a existência do terceiro ponto de contato: o apoio do espaço potencial no Eu. Esse apoio se evidencia numa ideia de Winnicott expressa numa passagem, na qual afirma que a constituição do objeto transicional e, portanto, do espaço potencial, se apóia nos primórdios da atividade mental, no emprego das satisfações auto-eróticas e no recordar, reviver, fantasiar e sonhar (WINNICOTT, 1971) todas as funções do Eu.

O exame do estatuto do instinto em Winnicott revela que este somente tem lugar importante num segundo momento da constituição do desenvolvimento emocional, quando o Eu já está constituído (JUNQUEIRA, 2010). Contudo, importante notar também que essa fase anterior, para a qual Winnicott chama a atenção, é uma fase que não se conclui, embora uma segunda fase — onde há a integração do Eu e onde os instintos começam a fazer sentido — já tenha se iniciado, enlaçando as duas. Essas proposições parecem indicar que Freud e Winnicott estão falando de dois níveis diferentes de apreensão do Self que se desenvolvem em paralelo. O primeiro tem relação com o desenvolvimento emocional, tal como descreve Winnicott: percurso da indiferenciação para a diferenciação, do objeto subjetivo ao objeto objetivamente percebido como forma de contato com a realidade etc. O outro tem relação com a constituição do aparelho psíquico, mais próximo das ideias freudianas: diferenciação tópica, trânsito da pulsão mediada pelos mecanismos de defesa etc. Essa ideia da existência de dois níveis que se relacionam de modo suplementar é muito relevante porque indica, a nosso ver, uma possibilidade e um limite nas aproximações 
que podemos fazer entre as teorias de Winnicott e Freud (JUNQUEIRA; COELHO JUNIOR, 2013).

Um segundo objeto que aparece no esquema apresentado, ao lado do somático, tem a intenção de contemplar a proposta de Green de que os objetos - e não apenas os estímulos endógenos que provêm do somático — fazem também uma exigência de trabalho ao psíquico, constituindo o que poderíamos denominar de "estímulo exógeno".

A estrutura enquadrante de Green, que se apresenta como o ponto de articulação entre as tópicas, é representada no esquema por todas as linhas, por todas as fronteiras. Grosso modo, a estrutura enquadrante é definida por Green (2008) como o espaço que surge dos movimentos de presença e ausência dos objetos. É o espaço responsável pela tradução das pulsões em representações psíquicas que dão materialidade às fronteiras psíquicas, formando a estrutura de base do psiquismo que permite a separação do objeto. Assim, é o que estabelece o conteúdo psíquico mediante um duplo limite Eu/pulsão e Eu/objeto exterior, funcionando como uma interface entre o intrapsíquico e o intersubjetivo. O não-psíquico pode estar, desse modo, contido pela estrutura enquadrante. Esses são os casos em que o não-psíquico está presente como continente da energia livre e de conteúdos clivados sem ser predominante na organização do sujeito; pois, quando são predominantes, pode haver uma ruptura da estrutura enquadrante. Em Winnicott, o espaço potencial depende exclusivamente da experiência de ilusão de onipotência e de desilusão progressiva. Já em Green, a constituição da estrutura enquadrante está ligada ao jogo entre pulsão e objeto, sem excluir a importância dos movimentos de presença e ausência do objeto implicados na ilusão/desilusão, mas enfatizando a importância da pulsão que objetaliza o objeto, que enlaça o objeto externo transformando-o em objeto psíquico. Assim, em termos tópicos, é possível traçar uma relação entre o aparelho psíquico e o espaço transicional onde a estrutura enquadrante opera como elo.

$\mathrm{Na}$ esteira de Brusset, esse esquema tem a intenção de representar uma proposta de concepção de aparelho psíquico e do Self comum a todos os sujeitos. Não se imagina que os processos de clivagem e o não-psíquico sejam uma exclusividade de certas patologias, mas, sim, que são predominantes nestas, e a sua localização tópica tem a intenção de ampliar a compreensão dessas patologias. Talvez, para uma melhor representação do que desejamos propor, fosse necessária a utilização de um modelo em três dimensões, ou quiçá em quatro dimensões, incluindo desse modo o trânsito entre os espaços ao longo do tempo.

Quanto ao trânsito entre os espaços, podemos imaginar pelo menos duas situações. Da esquerda para a direita, temos os movimentos constitutivos. Aqui, a excitação endossomática $\mathrm{X}$ vai de encontro ao objeto externo, as experiências com o objeto forjam representações que serão a matéria prima do psiquismo. 
Quando essa excitação não encontra objeto, ou seja, não encontra alívio ou satisfação na realidade, as representações de objeto não se formam e tudo o que pode ser transmitido ao psiquismo é apenas a cota de afeto, que, sem representação, será vivida como angústia (de intrusão e de perda do objeto, simultaneamente). A excitação endossomática se mantém irrepresentada ${ }^{4}$ e essa experiência não corrobora a constituição do Eu ou dos demais limites do psiquismo; a pulsão sem objeto fica retida, exercendo pressão sobre o psiquismo.

Da direita para a esquerda, temos os movimentos defensivos. Nesta, existe uma representação de objeto já constituída, no entanto, pelas vicissitudes do objeto (a passagem a um estado de ausência irrevogável, por exemplo), a qual resulta numa ação defensiva do aparelho psíquico, que expulsa a representação de objeto de seu interior através de um processo de recusa e de clivagem. Esse processo desarticula a representação, de forma que a pulsão antes ligada a ela retorne a um estado irrepresentado pela perda das articulações que garantem seu status de representação de coisa e de palavra. Resta então, tão somente, associações de objeto ou traços e uma cota de afeto que, desligada, será retida no não-psíquico e vivida como angústia. Nesta direção também estão, desse modo, os movimentos que, por sua força ou proporção, chegam a ser desarticuladores do psiquismo; nesta, a principal referência são as situações traumáticas. O que se deseja destacar aqui é que os elementos não-psíquicos podem tanto ser produzidos por uma parca constituição do psiquismo, como apontamos acima ao discorrer sobre a etiologia do funcionamento limite, como podem ser produzidos por reações defensivas diante de certas vicissitudes do objeto somadas às intensidades pulsionais promovidas pelas excitações endógenas e exógenas ao longo da vida.

Segundo o esquema apresentado, essa área relacionada à não-representação seria compreendida como não-psíquica. Estaria, assim, no seio do Self e, embora apartada, estaria indissociavelmente ligada ao funcionamento psíquico, o que nos faz pensar que, para os pacientes-limite, para os quais essa área é preponderante, devemos inverter a máxima de Botella, C. e Botella, S. (2002), escrevendo "somente fora, também dentro", mantendo o paradoxo entre a clivagem e a continuidade entre dentro e fora do psiquismo tão bem apontado por esses autores.

Como mencionamos acima, Brusset (2006) realiza uma ampla e importante revisão dos autores que tratam do tema da terceira tópica, à qual remetemos o leitor interessado em detalhes sobre o tema. Contudo, ele mesmo não procura realizar, a partir de suas considerações, uma representação gráfica da terceira

\footnotetext{
${ }^{4}$ Cabe destacar que aqui estamos fazendo referência apenas ao irrepresentado/representado, àquilo, que, nos moldes de Freud no Projeto... (1895) e no Inconsciente (1915), depende da experiência de satisfação com o objeto da realidade para se tornar objeto psíquico. Evidentemente, a discussão sobre o estatuto do irrepresentável encontra relação com a hipótese topográfica que procuramos sustentar. Contudo, a explanação dessas relações foge ao escopo deste artigo.
} 
tópica, tampouco inclui nessa revisão dois trabalhos que abordam o tema (o primeiro de modo indireto e o segundo de modo explícito), e que procuram apresentar um esquema tópico que merece menção: Laplanche (2003), com o conceito de "inconsciente encravado", inconsciente formado a partir das mensagens enigmáticas dos adultos e que permanece clivado através de um processo de recusa, predominante nos pacientes-limite; e Zuckerfeld (1992), cujo esquema contempla especialmente os efeitos dos processos de cisão, ainda que procure diferenciar a cisão fundante do aparelho psíquico e a cisão patológica.

A nosso ver, a primeira e a segunda tópicas freudianas são muito adequadas para a compreensão dos trânsitos psíquicos próprios dos quadros neuróticos, constituídos essencialmente a partir do Édipo e da castração, e bem sustentados numa clara diferenciação entre eu-outro, dentro-fora. Porém, os pacientes-limite e a "técnica modificada" proposta por Winnicott - e enriquecida pelas considerações clínicas e metapsicológicas de Green e outros autores, como Brusset e o casal Botella — nos remetem ao trabalho com o clivado, com o não-representado, com o narcisismo primário e com a constituição do objeto primário constante e digno de confiança, e sugerem, desse modo, necessidade de uma nova organização da tópica psíquica que dê conta da fronteira entre o psíquico e o não-psíquico; nova organização para a qual procuramos apresentar uma proposta de organização baseada na articulação das ideias desses mesmos autores.

A "técnica modificada", especialmente através da ideia de holding, permite a instalação de um objeto primário do qual se espera poder realizar um processo de luto que resulte na formação da estrutura enquadrante e nas identificações que constituem o Eu, base do duplo limite, sugerido por Green, onde se apoiarão de modo mais consistente a primeira e a segunda tópicas. Desse modo, os pacientes-limite e a técnica modificada dizem respeito a um trânsito psíquico que está aquém das tópicas freudianas, ainda que essa tópica anterior não seja condição de existência das tópicas freudianas, mas, sim, condição de seu bom funcionamento. A nosso ver, a reorganização tópica apresentada ajuda a compreender como certos mecanismos defensivos operam o esfacelamento do Eu e, por vezes, do aparelho psíquico, dado sua força e extensão. Também ajudam a sustentar a hipótese etiológica explicitada acima. Consideramos ainda que as articulações que puderam ser tecidas entre algumas das ideias de Freud, Winnicott, Green e Brusset, dentre outros, merecem ser pensadas em relação às suas implicações clínicas. Entretanto, por sua relevância e extensão, deixamos esses desenvolvimentos para outro trabalho, no qual possam ser adequadamente desenvolvidas.

Tendo então procurado sustentar, a partir da articulação de algumas idéias de Freud, Winnicott, Green e Brusset, uma hipótese etiológica para as patologias-limite como um tipo específico de neurose narcísica baseada num represamento da libido fora-do-psíquico e tendo organizado uma proposta de reorganização 
da tópica, também sustentada pelas idéias desses mesmos autores, esperamos tão somente ter contribuído para uma retomada da discussão da tópica que implica o campo da metapsicologia dos limites; fugindo do escopo desse artigo, uma revisão histórica ou mesmo uma discussão mais ampla da questão do irrepresentável relacionada, sem dúvida, a essa discussão. Ademais, de forma alguma se imagina ter chegado aqui a algo que não constituam tão somente hipóteses de trabalho provisórias, parte do desenvolvimento de um pensamento coletivo composto pelo rearranjo contínuo de ideias de tantos autores. Afinal, como bem nos lembra Freud, fazendo referência ao poeta Rückert, ao concluir seu texto Além do princípio de prazer (1920): “Ao que não podemos chegar voando, temos que chegar manquejando... o livro nos diz que não é pecado claudicar” (p. 85).

Recebido em: 2 de maio de 2014. Aprovado em: 19 de setembro de 2014.

\section{REFERÊNCIĀS}

ABRAHAM, N.; TOROK, M. The Shell and the Kernel: Renewals of Psychoanalysis. Chicago: University Press, 1994.

ANDRÉ, J. Transferência borderline. In: CARDOSO, M. R. (org.). Limites. São Paulo: Escuta, 2004.

BLUM, H. (1982) Theories of the Self and psychoanalytic concepts: discussion. J Am Psychoanal Assoc. 1982. N. 30, p. 959-78.

BOTTELA, C.; BOTTELA, S. Irrepresentável: mais além da representação. Porto Alegre: Criação Humana, 2002.

BRUSSET, B. Bulimia. São Paulo: Escuta, 2003.

. Métapsychologie des liens et troisième topique. Rev Franç Psychanal, 2006. N. 5, p. 1213-82.

. Névroses et États Limites. In: CHABERT, C. (org). Névroses et États Limites. Paris: Dunoud, 1999.

Psychanalyse du lien: les relations d'object. Paris: PUF, 2005.

FONAGY, P. An attachement theory approach to the treatment of the difficult patient. Bulletin of Menninger Clinic. 1998. V. 62, n. 2, p. 147-69.

; TARGET, M.; GERGELY, G.; ALLEN, J. G.; BATEMAN, A. The developmental roots of borderline personallity disorders in early attachment relationships: a theory and some evidence. Psychoanalitic Inquiry, 2003. N. 23, p. 3412-59.

FREUD, S. Libido Theory and narcissism - Conference XXVI. In:

The complete psychological works. The standard edition. London: Hogarth Press, 1975.

V. 16. Introductory lectures on psycho-analysis.

Press, 1975

The complete psychological works. The standard edition. London: Hogarth

The complete psychological works. The standard edition. London: Hogarth Press, 1975. V. 1. The Project for a Scientific Psychology. 
The complete psychological works. The standard edition. London: Hogarth

Press, 1975. V. 4. The interpretation of dreams.

The complete psychological works. The standard edition. London: Hogarth Press, 1975. V. 14. Mourning and melancholia. P. 237-58.

The complete psychological works. The standard edition. London: Hogarth

Press, 1975. V. 14. On narcissism: an introduction. P. 67-102.

The complete psychological works. The standard edition. London: Hogarth

Press, 1975. V. 18. Beyond the pleasure principle.

The complete psychological works. The standard edition. London: Hogarth

Press, 1975. V. 19. The Ego and the id.

GREEN, A. Conferências Brasileiras de André Green: metapsicologia dos limites. Rio de Janeiro: Imago, 1990.

Genèse et situation des états limites. In: André J. (org). Les états limites: Nouveu paradigma pour La psychanalyse? Paris: Press Universitaires de France, 1999.

La mère morte. In: Narcisisme de vie, Narcisisme de Mort. Paris: Les Editions de Minuit, 1980.

La penseé Clinique. Paris: Editions Odile Jacob, 2002.

O analista, a simbolização e a ausência no contexto analítico.

In Sobre a Loucura Pessoal. Rio de Janeiro: Imago, 1996.

Orientações para uma psicanálise contemporânea. Rio de Janeiro: Imago,

2008.

Vallon, 1995.

Propédeutique: la métapsychologie revisitée. Paris: Edition du Champ

Repérage originaire et transformations du lien de Freud a Winnicott. Rev Franç Psychanal. 2006. N. 5, p. 1569-75.

HAVENS, L. A theoretical basis for the concepts of self and authentic Self. J. Am. Psychoanal. Assoc. 1986. N. 34, p. 363-78.

JUNQUEIRA, C.; COELHO JUNIOR, N. Limites e possibilidades de diálogo: a teoria pulsional e a teoria das relações de objeto. Cadernos de Psicanálise do CPRJ. 2013. V. 35, n. 29, p. 89-104.

Rumo à "metapsicologia dos limites": o diálogo possível entre a teoria pulsional e a teoria das relações de objeto e algumas de suas consequências - Freud, Winnicott e Green. Tese de Doutorado. Instituto de Psicologia. Universidade de São Paulo. 2010.

KERNBERG, O. Borderline Personality Organization. J. Am. Psychoanal. Assoc. 1967. N. 15, p. 641-85.

Desordenes Fronterizos y Narcisismo Patológico. Buenos Aires: Paidós, 1985.

Psicoterapia focalizada en la transferencia: Psicodinámica de pacientes con organización de personalidad borderline. Una visión general. Tropicos - Rev. Psicoanál. 2001. V. 11, p. 73-95.

Severe personality disorders: psychotherapeutic strategies. New Haven and London: Yale University Press, 1984.

LAPLANCHE, J. Três acepções da palavra "inconsciente" no quadro da Teoria da Sedução Generalizada. Revista de Psicanálise (SPPA). 2003. V. 10, n. 3, p. 403-19. 
; PONTALIS, B. Vocabulário de Psicanálise. Rio de Janeiro: Imago, 1988. MAYER, H. Passagem ao ato, clínica psicanalítica e contemporaneidade. In: CARDOSO, M. R. (org). Adolescência: reflexões psicanalíticas. Nau Editora: Rio de Janeiro, 2001.

MEISSNER, W. W. (1986) Can psychoanalysis find its self? J. Ame. Psychoanal. Assoc. 1986. N. 34, p. 379-400.

MILLER, J-A. Os casos raros, inclassificáveis da clínica psicanalítica: a conversação de Arcachon. São Paulo: Biblioteca Freudiana Brasileira, 1998.

ROUSSILLON, R. A função limite da psique e a representância. Ver. Psicanál. SPPA. 2007. N. 14, p. 13-33.

Agonia e desespero na transferência paradoxal. Ver. Psicanál. SPPA.

2004. N. 11, p. 257-23.

Configuración de los estados limites. Rev. Psicoanál. 2008. V. 65,

p. 17-27.

SEARLES, H. My work with borderline patients. New York: Rowman \& Littlefield, 1986.

SOCOR, B. J. Conceiving the Self: presence and absense in psychoanalytic theory. Connecticut: International Universities Press, 1997.

TICHO, E. A. The alternate schools and the Self. J. Am. Psychoanal. Assoc. 1982. N. 30, p. 849-62.

VILLA, F. C.; CARDOSO, M. R. A questão das fronteiras nos estados limites. In: CARDOSO, M. R. (org.). Limites. São Paulo: Escuta, 2004.

WINNICOTT, D. W. Holding and interpretation: fragment of an analysis. London: Karnac Books, 1986.

Human Nature. London: Karnac Books, 1971.

Metapsychological and clinical aspects of regression within the psycho-analytical set-up. In: Collected Papers: Thought paediatrics to psychoanalysis, London: Karnac books, 1992.

Primitive emotional development. In: Collected Papers: thought paediatrics to psychoanalysis. London: Karnac books, 1945.

Psychiatric disorders in terms of infantile maturational process. In: The Maturational Process and the facilitating environment. London: Karnac Books, 1984.

ZUCKERFELD, R. Acto bulímico, cuerpo y tercera tópica. Buenos Aires: Paidós, 1992.

Camila Junqueira

camilajunqueira@gmail.com

Nelson Ernesto Coelho Junior

patnelco@uol.com.br 
